\title{
Entretecendo Vozes na (Re)Escrita de Diários Reflexivos de Professores de Línguas em Formação Jnicial
}

Weaving Voices in the (Re)Writing of Reflexive Diaries by Language Teachers in Initial Formation

Cristiane Carvalho de Paula BRITO*

Resumo: Ancorados na Análise do Discurso de linha francesa em sua interface com a Linguística Aplicada, este trabalho se propõe analisar o processo de (re)escrita de diários reflexivos produzidos por professores em formação inicial, no estágio supervisionado de língua inglesa, a partir das intervenções feitas pela professora supervisora. Parte-se do pressuposto de que tal processo se orienta pela alteridade, isto é, pelo jogo de imagens (de si, do outro, da escrita etc.) que inevitavelmente se estabelece nos contextos enunciativos. Nesse sentido, por meio de um gesto de leitura que leva em conta a opacidade da linguagem e a heterogeneidade dos sujeitos, interessamnos investigar não somente os recursos linguístico-textuais utilizados pelos sujeitos na reformulação de seus textos, mas sobretudo as representações que os professores em formação inicial fazem acerca desse gênero e que incidem na organização de seus dizeres e na mobilização de vozes oriundas de diferentes regiões discursivas. Por fim, propomo-nos também problematizar a relevância do gênero diário reflexivo na formação do professor e o papel da escrita como instrumento formador.

Palavras-chave: Produção escrita. Representações. Formação de professor.

Abstract: Based on the articulation of French Discourse Analysis with Applied Linguistics, this work aims at analyzing the process of (re)writing of reflexive diaries produced by teachers in initial formation, in the context

\footnotetext{
* Mestre (2004) e Doutora (2009) em Linguística Aplicada pela Universidade Estadual de Campinas (UNICAMP). É professora da Universidade Federal de Uberlândia (UFU). Contato: depaulabrito@gmail.com.
} 
of English teaching supervised internship, from the interventions made by the supervisor teacher. We start from the assumption that this process is oriented by alterity, that is, by the game of images (of oneself, of the other, of writing etc) which is inevitably established within the enunciative contexts. Thus, from a gesture of reading that considers the opacity of language and the heterogeneity of subjects, we are interested in investigating not only the linguistic and textual resources used by the subjects when rewriting their texts, but particularly the representations that teachers in initial formation have concerning this genre and that influence in the organizations of their sayings and in the mobilization of voices from different discursive regions. For that, we also propose to problematize the relevance of the genre reflexive diary in teacher formation and the role of writing as formative tool.

Key-words: Writing production. Representations. Teacher education.

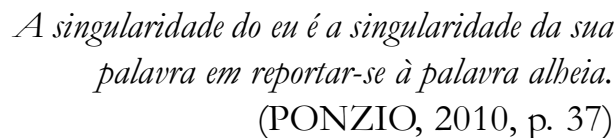

\section{Inquietações Iniciais}

Neste trabalho, tomamos diários reflexivos escritos por professores em formação inicial durante o estágio supervisionado de língua inglesa, no intuito de analisar o processo de (re)escrita desenvolvido a partir das intervenções feitas pela professora supervisora ${ }^{1}$. Fundamentamo-nos no quadro teórico-metodológico da Análise do Discurso (AD) pecheutiana em sua interface com a Linguística Aplicada (LA) e partimos do pressuposto de que o processo de (re)escrita se orienta pela alteridade, isto é, pelo jogo de imagens (de si, do outro, da escrita etc.) que inevitavelmente se estabelece nos contextos enunciativos.

${ }^{1}$ Esse trabalho é fruto das reflexões que temos desenvolvido a partir da articulação do projeto 'Formação de professores de línguas: (re)pensando dizeres, construindo saberes', na Universidade Federal de Uberlândia, com o projeto 'Formação inicial de professores mediada pela escrita' (CNPq n $\left.{ }^{\circ} 400458 / 2010-1\right)$, coordenado pelo prof. Dr. Wagner Rodrigues Silva. 
É a partir do século XIX que se percebe, com maior intensidade, o uso do diário como forma de permitir a expressão dos conflitos interiores vivenciados pelos indivíduos na época (MACHADO, 1998). Dentro do processo de ensino-aprendizagem e nos contextos de formação de professores, o uso do gênero diário coincide com a valorização da escrita e da pesquisa (auto)biográficas, a partir da década de 1970, fruto, por sua vez, do deslocamento de um paradigma mais estruturalista para um mais humanista na ciência, que valoriza o sujeito e sua história, em detrimento da racionalidade.

Nos estudos dedicados à investigação do gênero diário, percebe-se que, conforme suas características e objetivos, encontram-se as seguintes nomenclaturas: diários íntimos/compartilhados (HILÁ, 2008), diários descritivos (ALLWRIGHT; BAILEY, 1991), diários de leitura (MACHADO, 1998), diários colaborativos (BROCK; JU; WONG, 1991), dentre outras. $\mathrm{E}$, de forma geral, em relação às suas contribuições e/ou funções, os diários têm sido concebidos como um espaço para: explicitar incertezas e ansiedades de professores em formação, gerando novas ações pedagógicas; produzir uma escrita mais espontânea e natural; promover a autorreflexão e conscientização de ações; registrar experiências (HILÁ, 2008); compreender a percepção que os sujeitos investigados possuem acerca dos processos cognitivos, sociais e afetivos experienciados no ensino-aprendizagem de línguas estrangeiras (NASCENTES, 2008); promover a transformação e reflexão crítica do sujeito (LIBERALI, 1999).

Intitulados como 'reflexivos' ou não, os diários têm sido comumente compreendidos como um instrumento que possibilita a atitude de introspecção, (auto)avaliação, conscientização, crítica e transformação. Percebe-se que as considerações de Smith (1992) sobre as quatro ações necessárias ao desenvolvimento da reflexão crítica - descrever, informar, confrontar e reconstruir - aparecem, com frequência, como eixo orientador dos estudos sobre o uso de diários no contexto de ensino-aprendizagem de línguas.

Apesar de não descartarmos a possibilidade de os diários configurarem-se como lugar de reflexão, ressaltamos que nos distanciamos da concepção de sujeito que comumente subjaz a tais propostas. Trata-se de uma noção de sujeito cartesiano, centrado, capaz de monitorar todas as suas ações e, consequentemente, transformá-las. Nesse sentido, é necessário pontuar que entendemos a 'reflexão' não como a possibilidade de total 
consciência de si ou dos outros, e sim como a possibilidade de deslocamentos discursivos (BRITO, 2012). A reflexão não consiste, pois, em um processo linear, controlável ou previsível, uma vez que o sujeito, como efeito de linguagem, se vê na impossibilidade de ocupar uma posição de exterioridade em relação a esta (AUTHIER-REVUZ, 2004). Concordamos, assim, com Coracini (2003, p. 317), quando afirma que a "vertente que prega a formação reflexiva do professor é atravessada pela visão cognitivista, linearizante e homogeneizante da aprendizagem, pela concepção de linguagem transparente - e pela concepção de sujeito centrado, consciente e inteiro (completo)".

Dito de outra forma, concebemos o diário reflexivo não como um texto "livre de amarras" - em que o enunciador poderia dizer 'tudo' o que pensa - haja vista que a natureza clivada do sujeito e a equivocidade linguagem arruínam qualquer tentativa de totalização e completude, fazendo emergir as contradições, as falhas, as fissuras, marca do movimento dos sentidos na história.

Portanto, o olhar que aqui lançamos para o processo de (re)escrita dos diários é marcado por um gesto de leitura que leva em conta a opacidade da linguagem e a heterogeneidade dos sujeitos, o que, por sua vez, nos interpela a investigar não somente os recursos linguístico-textuais utilizados na reformulação dos textos, mas sobretudo as representações que os professores em formação inicial fazem acerca desse gênero e que incidem na organização de seus dizeres e na mobilização de vozes oriundas de diferentes regiões discursivas. Além disso, propomo-nos também problematizar a relevância do gênero diário reflexivo na formação desse professor e o papel da escrita como instrumento formador.

Para dar conta das questões que elencamos, o presente artigo se organiza da seguinte forma: primeiramente, faremos algumas considerações sobre o quadro teórico-metodológico que fundamenta nossa tomada de posição em adotar uma perspectiva inter/transdisciplinar ancorada na articulação da AD francesa e da LA. Em seguida, discutiremos nosso gesto de interpretação em relação ao corpus; e, finalmente, teceremos comentários, a fim de responder algumas inquietações levantadas no texto.

\section{Algumas Palavras sobre a Urdidura Teórico-Metodológica}

Sem a pretensão de exaurir os constructos teórico-metodológicos que sustentam não apenas a forma como olhamos para nosso corpus, mas 
também como o construímos, nosso propósito aqui é antes o de problematizar o lugar de entremeio da LA e da AD, perscrutando as (im)possibilidades desse encontro-confronto. Pensar as práticas de linguagem que permeiam a formação de professores a partir da inscrição na $\mathrm{AD}$ de linha francesa, a nosso ver, implica em assumir certos riscos. Expliquemo-nos.

A $\mathrm{AD}$ recusa uma visão meramente instrumental de linguagem para concebê-la como constituinte dos sujeitos. Trata-se, pois, de uma noção de língua permeada pela falha, pela falta, pela (in)completude vinda do confronto entre a historicidade do dizer e o contexto de enunciação, entre a estrutura e o acontecimento. Trata-se da "língua da indefinição do direito e avesso, do dentro e fora, da presença e ausência” (FERREIRA, 2005, p. 17).

Ademais, a AD também rejeita uma concepção cartesiana e centrada de sujeito, pilares epistemológicos dos estudos desenvolvidos na Linguística e na LA, como salientam Bohn (2005), Moita Lopes (2006) e Rajagopalan (2006). O sujeito da AD, ao contrário, constitui-se no imbricamento da língua, da história, da ideologia, do inconsciente e nos esquecimentos (de que não é fonte de seu discurso nem senhor de seu dizer) ${ }^{2}$.

Colocando em movimento tais noções, assume-se o risco de abrir mão da ilusão de controle - dos sentidos, dos dizeres, do processo de ensino-aprendizagem, enfim, da própria linguagem - para aceitar a instabilidade (e, por que não dizer, o desconforto) causada pela polissemia, pela dispersão e unidade dos sentidos, pela polifonia e pelo dialogismo (para ressaltar Bakhtin). Instabilidade que, sendo fruto da não transparência da linguagem e do esfacelamento do sujeito, faz da tomada da palavra - e, consequentemente, do significar(-se) - um espaço fluido, movediço, tenso.

Assim, antes de 'tomar' como corpus de análise os diários reflexivos produzidos por sujeitos professores em formação inicial, é necessário dizer que compreendemos que tais sujeitos são 'tomados' pelas representações que constroem sobre si e sobre o(s) outro(s), isto é, por um jogo de projeções colocado em funcionamento no/pelo discurso (PÊCHEUX, 1997b). Não poderíamos, pois, ignorar as demandas que a própria instituição impõe acerca dessa prática de linguagem. Dito de outro modo, não podemos

${ }^{2}$ Referimo-nos aos esquecimentos n. 1 e n. 2, tais como formulados por Pêcheux (1997a). 
perder de vista que a escrita desse sujeito se dá na tensão entre imagens diversas: a imagem que tem sobre o gênero diário reflexivo; a imagem que tem que o sujeito professor tem acerca desse gênero; a imagem que faz de seu leitor/interlocutor; a imagem que constrói acerca de si mesmo enquanto sujeito-aprendente e sujeito-ensinante.

Observe-se que aqui preferimos utilizar os termos 'sujeito-ensinante' e 'sujeito-aprendente', para nos referirmos, respectivamente, ao professor e ao aluno, por compreendermos que eles estreitam a interface entre a LA e a $\mathrm{AD}$, já que a terminologia 'ensinância' e 'aprendência' marca, por parte de tais sujeitos, a "dinâmica interacional do processo de ensinar e aprender, estabelecendo relações interativas de desejo, motivação, absorção, produção, construção e criação" (SANTOS, 2006, p. 25). A partir dessa perspectiva, é possível conceber os sujeitos envolvidos no ensino em movência, ou seja, na constante possibilidade de deslocamentos discursivos, e não fixados em lugares estanques e delimitados.

Ainda sobre o nosso referencial teórico, insistimos em postular esse lugar de entremeio da LA e da AD com vistas a defender uma LA que abandone o "caráter solucionista" que a acompanhou durante anos (MOITA LOPES, 2009, p. 19), e que seja responsiva à vida social, constituindo-se no hibridismo, na transgressão de limites, na trans/inter/indisciplinaridade. Tal visão parece-nos, fundamentalmente, começar pela problematização das noções de sujeito e linguagem que se adotam nas práticas de pesquisas científicas, nos processos de formação de professores e no ensino de línguas. Aliás, podemos afirmar que essa problematização se inicia ao se considerar que toda e qualquer forma de construção do saber é um processo discursivo, em que alguns dizeres e saberes são consolidados, enquanto outros são simplesmente apagados ou silenciados. Portanto, falamos desse entremeio por nos sentirmos interpelados a desenvolver uma AD e uma LA que sejam, antes de tudo, uma prática política, que, em nosso caso, se empenhem em pelo menos tentar lançar outros olhares para a formação de professores e para os processos de ensino-aprendizagem de línguas. 


\section{A Trama, a Urdidura e os Fios}

\subsection{Sobre as condições de produção do corpus}

Os diários reflexivos aqui analisados foram produzidos por professores de língua inglesa em formação inicial em uma universidade pública no interior de Minas Gerais, durante a disciplina de estágio supervisionado de língua inglesa, ministrada por nós, no período de 2010 a $2011^{3}$.

Os professores em formação receberam, no início da disciplina de estágio, um plano de avaliação em que foram orientados a redigir três diários reflexivos baseados em aulas ministradas por eles, considerando aspectos como: clareza e coesão do texto; descrição de aspectos e eventos relevantes da aula; posicionamento sobre os fatos ocorridos na sala de aula; confronto entre o planejamento e a aula dada; confronto da prática e teorias estudadas / consultadas ao longo do curso de Letras; e reconstrução / apresentação de sugestões. Além de possibilitarem, ao futuro professor de língua inglesa, outro olhar sobre sua prática e sobre sua formação como um todo, os diários também cumprem a função de informar, ao professor supervisor de estágio, acerca do andamento das aulas ministradas por cada professor em formação, já que aquele não pode realizar o acompanhamento individual de todas as aulas. Ressaltamos, ainda, que, apesar de não ter sido um aspecto obrigatório dentro do plano de avaliação, os professores em formação foram encorajados a redigirem os diários ao longo da disciplina, isto é, antes da data final estipulada, para que fosse possível haver orientação e tempo para sua reescrita.

Em Brito (2012), com base na análise de aproximadamente 87 diários produzidos por 28 professores estagiários, discutimos os atravessamentos discursivos que vêm à tona na escrita desse gênero e que sustentam a construção de certas representações ${ }^{4}$. Para a investigação do processo de

${ }^{3}$ Salientamos que, até 2010, a disciplina era denominada de 'Prática de Ensino de Língua Inglesa'.

${ }^{4}$ Investigamos, no trabalho citado, as representações construídas pelos sujeitos acerca: do outro; da aula de língua inglesa; de plano de aula; de si, enquanto professor estagiário de língua inglesa. 
reescrita, entretanto, analisamos 14 diários, produzidos por 6 professores, os quais nos foram enviados por e-mail, lidos e respondidos com os devidos comentários.

Nossa investigação foi balizada pelas seguintes perguntas:

(i) Que tipo de intervenções são feitas pela professora supervisora do estágio?

(ii) Que vozes são evocadas pelo professor de língua inglesa em formação inicial, na reescrita de seus diários reflexivos, a partir das intervenções feitas pela professora supervisora do estágio?

(iii) Que tipo de alterações são feitas nos diários reflexivos quando há intervenção da professora supervisora de estágio?

(iv) Que imagem de escrita é mobilizada pelo sujeito professor em formação inicial a partir do processo de reescrita?

(v) As intervenções da professora supervisora contribuem para o processo de (re)escrita dos diários reflexivos?

A fim de proceder ao nosso gesto de leitura, separamos as sequências selecionadas para análise em três momentos: no primeiro (VI = versão inicial), expusemos o recorte do diário sobre o qual incidiu o comentário, colocando em itálico o trecho que especificamente recebeu a intervenção; no segundo, apresentamos as considerações tecidas pela professora supervisora $(\mathrm{CP}=$ comentários da professora); e, finalmente, explicitamos a versão final do diário (VF), após a intervenção da professora supervisora, deixando em itálico os trechos que, a nosso ver, melhor ressaltam a análise que desenvolvemos.

\subsection{Gestos de leitura}

\subsubsection{Diário 1: Antonieta}

VI: Essa aula também saiu um pouco do tradicional do que vemos nas aulas de língua estrangeira e pôde contribuir para uma formação crítica desses adolescentes. (Fim do diário de Antonieta ${ }^{5}$ )

CP: Explore mais esse comentário...

${ }^{5}$ Salientamos que todos os nomes colocados ao final dos recortes são fictícios. 
VF: [...] adolescentes. Quando falo sobre algo tradicional, refiro-me ao estilo comum às aulas de linguas estrangeiras: explicações de conteúdo gramatical, exploração escrita e oral desse conteúdo, uso de informações descontextualizadas, uso de um livro didático que pode ou não atender aos objetivos do professor e aos do aluno. Ao usar um texto acadêmico, os alunos tiveram a oportunidade de entrar em contato com essa lingua de uma forma menos controlada, mais aberta para que eles mesmos produzissem sentidos e interagissem com esse conteúdo que lhes foi apresentado.

Ao ser interpelada a explorar mais a afirmação do que seja 'tradicional', Antonieta acrescenta, na reescrita de seu diário, e logo após o período em questão, algumas informações. Parece-nos relevante que, ao comentar sobre a aula que ministrou, a professora em formação inicial mobilize uma imagem de ensino de língua (e, por que não dizer, de escola) bastante consolidada em cursos de formação e na sociedade em geral: o de que a sala de aula é o lugar do tradicionalismo. $\mathrm{Na}$ reescrita de seu diário, Antonieta explicita o que entende por 'tradicional' e projeta sua aula justamente em contraposição a essa imagem, sem, contudo, 'refletir' sobre tal conceito.

Está posto para esse sujeito que uma aula tradicional de língua inglesa restringe-se ao ensino descontextualizado da gramática. Observe-se que o simples uso do livro didático já é tido, no fio do dizer desse sujeito, como um elemento característico da abordagem tradicional. Isto é, apaga-se o fato de que um livro didático que atenda "aos objetivos do professor e aos do aluno" e, eventualmente, promova o "contato [...] de forma menos controlada", possa "contribuir para uma formação crítica desses adolescentes". Assim, o que irrompe, no intradiscurso, é a memória discursiva que constitui o sujeito.

Afirmamos que não houve de fato reflexão sobre o conceito de 'tradicionalismo', uma vez que a suposta 'inovação' da aula de Antonieta estaria no uso de um "texto acadêmico". Contudo, não se dá a conhecer ao leitor o que de 'não tradicional' foi feito com tal texto em sala de aula; apenas se reitera, por meio de expressões como "forma menos controlada", "produzissem sentidos" e "interagissem", o lugar de distanciamento que o sujeito procura ocupar em seu dizer acerca de uma prática ou abordagem supostamente criticada na academia. 


\subsubsection{Diário 2: Letícia}

VI: Um último aspecto a ser comentado, enquanto professora, é tentar ter um ritmo mais acelerado dentro da sala de aula. (Fim do diário de Letícia)

CP: Vejo você dialogando aqui comigo, mas no seu texto esse comentário ficou meio solto. Explique melhor.

VF: [...] dentro de sala da sala de aula, mais dinâmico, para que os alunos não fiquem parados, mas, sim, incentivá-los a participar da aula, tais como: exercícios em duplas, constante apresentação em slides, pois isso chama a atenção deles, ao corrigir exercícios, fazer perguntas aos alunos de forma aleatória para que todos fiquem antenados para quando chegar sua vez, enfim, oferecer-lhes uma aula menos monótona, em que apenas o professor fala, e os alunos escutam.Entretanto, quanto ao ritmo, acredito que isso tem relação com a personalidade do professor e também pelo fato de os alunos ainda não se conhecerem bem, já que eles não estudam juntos na escola regular. Creio que com o decorrer do curso, as conversinhas paralelas irão surgir e como terei mais intimidade, os alunos se sentirão mais à vontade, tanto para participarem ativamente, esclarecerem as dúvidas em sala de aula, como para ficarem mais descontraídos, assim como eu. Ademais, gostei muito da experiência de dar minha primeira aula de inglês! Veremos como as outras aulas irão prosseguir...

Em seu diário, Letícia traz a voz da professora supervisora ao mencionar um comentário feito por esta durante, o feedback fornecido acerca de sua aula ministrada no estágio. Ao destrinchar a afirmação feita na primeira versão do diário reflexivo, Letícia acrescenta algumas informações, ressignificando os comentários feitos pela professora e mobilizando a voz do discurso pedagógico acerca do ensino de línguas que, sabe-se, preza pela 'interação' (e não por situações “em que apenas o professor fala, e os alunos escutam”), pelo 'movimento' ("mais dinâmico", "alunos não fiquem parados”), pela 'inovação' (“aula menos monótona”) e, atualmente, poderíamos mencionar, pela 'inclusão tecnológica' ("constante apresentação em slides").

Todavia, é interessante notar que ela marca um lugar de resistência em relação às vozes que foi interpelada a evocar para atender à solicitação da professora ("isso tem relação com a personalidade do professor"). Ou 
seja, há um posicionamento do sujeito acerca de uma possível imposição, feita pela supervisora, de um 'estilo de ensinar'. Na reescrita do diário de Letícia, pode-se, pois, flagrar a tensão que a constitui enquanto sujeito que ocupa o lugar de aprendente-ensinante e que, portanto, precisa mobilizar aspectos identitários de ambos os lugares ("ficarem mais descontraídos, assim como eu", "experiência de dar minha primeira aula de inglês").

\subsubsection{Diário 3: Laísa}

VI: Quando terminei de sanar as dúvidas, fiquei muito frustrada, pois, quando preparei a aula, estava com a certeza que seria perfeita. Chegando no dia da aula, quando começou a ocorrer esses pequenos problemas, fui ficando nervosa e começava a gaguejar.

CP: Em que sentido? Existe aula perfeita? Quais? Por quê?

VF: [...] perfeita. Não considero perfeita, porque na minha concepção, não existe aula perfeita. Quando refiro à palavra perfeita, quero dizer no sentido de tudo que eu planejei no papel, eu conseguir colocar e prática. Chegando no dia da aula, quando começou a ocorrer esses pequenos problemas, de aluno ficar com dúvida e não me perguntar, fui ficando nervosa e começava a gaguejar. Não tem uma aula que não reforce a questão da dúvida, que se caso eles tiverem que podem me procurar que eu vou ajudar o quanto possivel for.

Laísa é questionada, pela professora supervisora sobre o que entende ser uma aula perfeita. Vê-se que, na versão final de seu diário, ela pontualmente responde à indagação da professora, e, apesar de reformular a ideia inicial ("não existe aula perfeita"), o faz sem alterar a estrutura primeira. Além disso, pouca problematização houve acerca do que de fato venha a ser uma aula perfeita, ou seja, Laísa parece restringir-se a "resolver" o suposto problema apontado pelo interlocutor.

Da mesma forma, pode-se notar que a explicitação dos "pequenos problemas" que ela menciona ter encontrado aparece por meio de uma oração inserida justamente no ponto de questionamento feito pela professora (“de aluno ficar com dúvida e não me perguntar"), sendo acrescentada, logo em seguida, a explicação do fato de ela ter ficado nervosa.

Há, todavia, um silenciamento, na versão final do diário, da razão do nervosismo (d)enunciado pelo sujeito, o qual se dá, a nosso ver, justamente 
pela tensão causada no embate entre a posição discursiva de aprendente x a posição discursiva de ensinante. Por que, por exemplo, o fato "de aluno ficar com dúvida e não me perguntar" leva Laísa, inclusive, a "gaguejar"? Quem detona esses sintomas de ansiedade no sujeito? A professora que observa (e avalia); o aluno que, por motivos que não se dão a conhecer (ao leitor?, ao professor estagiário?), não tira suas dúvidas com a professora estagiária; ou a ilusão de completude e, ao mesmo tempo, a percepção da falta desse sujeito, que conhece a limitação do próprio conhecimento que tem da língua, mas que se esforça o "quanto possível for"?

Nesse sentido, é para 'amenizar' e silenciar esse (inevitável) embate que se constrói perante o outro (interlocutor-avaliador) a imagem de 'bom professor' ("vou ajudar o quanto possível for"), acarretando o esvaziamento argumentativo do texto, como se pode observar no diário seguinte.

\subsubsection{Diário 4: Dalva}

VI: Tentei dar início à aula da maneira mais natural possível, pois eu estava sendo observada, e isso, querendo ou não, acabou me deixando um pouco desconcertada. Fiz uma pequena revisão da aula anterior e dei início a minha aula no tempo previsto.

CP: O que significa "maneira mais natural possível"? Por quê?

VF: Tentei dar início à aula da maneira mais natural possível, pois en estava nervosa por estar sendo observada pela professora orientadora, e isso, querendo ou não, acabou me deixando um pouco desconcertada, pois não sabia o que a orientadora estava achando da minha aula: se eu estava me saindo bem ou mal. Fiz uma pequena revisão da aula anterior e dei início a minha aula no tempo previsto.

No diário de Dalva, o embate entre a posição discursiva de aprendente $\mathrm{x}$ a posição discursiva de ensinante emerge já na primeira versão do diário reflexivo ("pois eu estava sendo observada") e pode ser flagrado na versão final ("se eu estava saindo bem ou mal"), quando a imagem de 'boa aula' (que se inicia no "tempo previsto", consolidando, aliás, a representação de 'total controle da situação' por parte da estagiária) novamente tenta silenciar aquilo que a constitui e interpela.

A "necessidade de manter implícita uma imagem à qual o sujeito está ligado" (FAIRCHILD, 2010, p. 277, grifo do autor) é, pois, evidente na sequência 
discursiva selecionada e, como dissemos anteriormente, fragiliza a posição de sujeito enunciador. Fazemos coro às palavras de Fairchild (2010), cujas considerações sobre os relatórios de estágio supervisionado parecem-nos apropriadas para a análise dos diários reflexivos. Em suas palavras:

[...] o relatório é um enunciado no qual certos elementos não podem ser lidos como se tivessem um valor puramente referencial, porque sua ocorrência se deve antes a uma tentativa de gerenciar os aspectos interacionais e pragmáticos da interlocução entre o estagiário e seu professor. Esses aspectos precisam ser percebidos pelo professor de estágio para que certos movimentos de caráter argumentativo não sejam lidos nem como se fossem dados objetivos, nem como se fossem simples fruto de uma intenção consciente. Pelo contrário, há certos movimentos da escrita que enlaçam, mesmo sob a aparência de argumentos banais, aquelas imagens fundamentais para a constituição de um sujeito. É possível que, para um sujeito, falar em formação seja o mesmo que falar na sua necessidade de passar por essas imagens e elaborar uma solução para os conflitos que elas trazem em que os recursos fornecidos por uma determinada área do saber, na qual ele se especializa, tenham lugar de proeminência. (FAIRCHILD, 2010, p. 287, grifos do autor)

\subsubsection{Diário 5: Alexandra}

VI: Se pudesse voltar atrás, descartaria alguns exercícios repetitivos que o livro didático propõe e trabalharia mais calmamente com os alunos os conteúdos básicos da unidade, tendo mais tempo para explicar e checar se realmente foram entendidos e assimilados pelos alunos. Estou refletindo em como evitar este problema na próxima aula.

CP: Por que não colocar algumas sugestões já aqui?

VF: Para a próxima aula talvez eu ignore alguns exercícios do livro, adote um ritmo mais lento, trabalhe o conteúdo com mais atividades para fixação e compreensão. Estou refletindo em como evitar o problema ocorrido nesta aula.

A professora supervisora solicita a Alexandra que destrinche a afirmação de que estaria refletindo sobre um problema ocorrido na aula. 
Vê-se que a aluna atende à intervenção e acrescenta, antes do período final de seu diário, um trecho explicativo: "para a próxima aula talvez eu ignore alguns exercícios do livro, adote um ritmo mais lento, trabalhe o conteúdo com mais atividades para fixação e compreensão”.

Mais uma vez, pode-se perceber o quão pontual e situada é a alteração feita pela professora em formação na versão final do diário. Todavia, o que nos inquieta é justamente o fato de o sujeito enunciador utilizar o espaço de um diário chamado reflexivo, para anunciar - sem, contudo, efetivar - sua reflexão sobre uma determinada situação. Ou seja, o diário parece não se configurar como um lugar para (des)construção de sentidos e problematização das próprias práticas pedagógicas experienciadas durante o estágio.

Por outro lado, também poderíamos questionar se a intervenção feita pela professora supervisora, a saber, a insistência ou expectativa de obter respostas da estagiária, não evidenciaria sua ilusão de controle e completude. Dizer que se está refletindo não seria já marca da percepção dessa professora de que algo falta, ainda que não se saiba nomear ou explicar? E trazer tal inquietação à tona não seria propício em um diário reflexivo?

\subsubsection{Diário 6: Pietra}

CP: Pietra, acho que você está no caminho certo, mas você pode explorar mais a questão do uso (ou não uso) da língua por você e pelos alunos, a aula em si etc.

VF: Como eu já conhecia a maioria da turma me senti a vontade para utilizar a língua inglesa o tempo todo. Eles entenderam bem e não tiveram grandes dificuldades em me compreender. Sempre há os alunos que querem que o professor traduza tudo mas tento utilizar outros recursos, parafrasear o que eu disse, pedir para algum colega explicar o que entendeu, de forma a facilitar a compreensão dos demais alunos. (Trecho acrescentado ao final do diário de Pietra)

Finalmente, no diário de Pietra, em que não houve nenhuma intervenção ao longo do texto, mas apenas ao final, o que vemos é justamente o atendimento à solicitação feita pela professora supervisora, feita pelo acréscimo de dois parágrafos na última versão do diário. 
Ao discorrer sobre a relação língua inglesa / língua materna, pode-se notar, na necessidade de se justificar perante o seu interlocutor, o 'desconforto' que o uso da língua materna lhe causa ("utilizar a língua o tempo todo", "tento utilizar outros recursos"). Pietra evoca, assim, o discurso de metodologias de ensino de línguas (como, por exemplo, o audiolingualismo e o método direto), que não veem com bons olhos o uso da língua materna em aulas de língua estrangeira, para justificar as estratégias que usa, caso haja necessidade de traduzir para "facilitar a compreensão dos demais alunos". Observe-se que a tradução aparece, no fio do dizer, como um último recurso e é feita, de preferência, por "algum colega" (e não pelo professor), a quem seria dada a permissão de "explicar o que entendeu", em português.

Novamente, é a imagem de 'bom professor' (e, consequentemente, de 'boa aula') que parece ser mobilizada no texto de Pietra.

\section{Inquietações (In)Conclusivas}

Voltemos às perguntas que elencamos anteriormente, a fim de tentar, senão respondê-las, ao menos lançar alguns olhares sobre nossas inquietações e, assim, vislumbrar possíveis caminhos a serem traçados.

Em relação às intervenções feitas por nós, como professora supervisora de estágio, pode-se dizer que boa parte das intervenções vão no sentido de encorajar o sujeito professor em formação inicial a desenvolver as ideias apresentadas, a questionar as meras descrições, a confrontar a sua aula com o planejamento/teoria, a pensar no uso da língua materna e da língua estrangeira no espaço da sala de aula, etc.. É preciso salientar que não cremos na 'neutralidade' de nossas intervenções, pelo contrário, entendemos que elas são traspassadas pelo lugar (teórico-histórico-político-social) do qual falamos, pelas tomadas de posição que empreendemos e nos marcam enquanto sujeito constituído por várias vozes. Dessa forma, olhar para nossas próprias intervenções é estar ciente de que no "próprio" escapam-se-nos $\mathrm{o}(\mathrm{s})$ outro(s).

Ao (re)escrever os diários reflexivos, os sujeitos evocam as vozes da professora supervisora (acerca, por exemplo, da aula que ministraram), as vozes que os constituem enquanto aprendizes de línguas estrangeiras, as vozes do discurso pedagógico para o ensino de línguas, dentre outras. Vê-se que eles tentam articular tais vozes, movendo-se na e pela tensão causada entre a imagem que têm de seu interlocutor e de si mesmos enquanto 
sujeitos-aprendente-ensinante. Dito de outra forma, entendemos que o gênero diário reflexivo não é um espaço em que o professor em formação simplesmente discute ou registra suas impressões e percepções acerca das aulas que ministrou, antes, sendo um texto dirigido a um leitor que é, inevitavelmente, um avaliador (ainda que não atribuísse notas), diríamos que o diário é um lugar de conflitos, de (des)ajustes de sentidos e (des)construção de imagens.

Quanto ao tipo de alterações feitas nos diários reflexivos quando há intervenção da professora supervisora, notamos que elas são, de forma geral, bem pontuais e localizadas'. As alterações basicamente aparecem como respostas às intervenções; não há retextualização como um todo da primeira versão do texto, e sim um acréscimo (ou subtração) de informações, conforme a solicitação da professora.

No que diz respeito à imagem de escrita mobilizada pelo sujeito professor em formação inicial a partir do processo de reescrita, diríamos que predomina a representação de escrita como tarefa escolar, a qual se resume em um 'produto agradável ao professor'. Aliás, é para nós muito significativo o fato de termos contado, dentro do universo de cerca de mais de 20 sujeitos, com os textos de apenas seis professores para empreendermos o nosso gesto de leitura. Tal dado numérico corrobora a imagem de escrita como produto. Em outras palavras, não se concebe a escrita como processo de interlocução e, portanto, refacção. Balizados pela necessidade de construir a imagem de 'bom professor', os sujeitos deixam de perscrutar outros dizeres e memórias discursivas e escrevem para um avaliador, para o qual bastaria mostrar que se dominam as 'regras do jogo'.

Finalmente, ao pensar sobre as contribuições de nossas intervenções para o processo de (re)escrita dos diários reflexivos, arriscamo-nos a dizer que, apesar de nossas análises mostrarem alterações muito pontuais nos textos, parece haver uma tentativa, ainda que tímida, de mobilização de outros olhares e pontos de vista (inclusive de resistência, como no diário de Letícia). $\mathrm{Na}$ verdade, ousaríamos dizer que as intervenções oferecem a possibilidade da 'reflexão', da desnaturalização das evidências, da problematização do que é posto como óbvio, o que pode incidir sobre a prática pedagógica. Não apenas sobre aquela realizada durante o estágio - no geral, tão "curta” - mas, na prática, enquanto processo contínuo e sempre inacabado de formação. 
Com isso queremos dizer que não esperamos uma "aplicação automática" entre a intervenção da professora e a prática do sujeito professor em formação, mas entendemos que o diálogo - na acepção bakhtiniana - é o único caminho capaz de produzir trans-formação. É no e pelo diálogo que caminhos outros se aventam aos sujeitos, sem que se possa saber ao certo onde vão culminar. Aliás, a formação de professores não deveria ser vista como um lugar (ideal) aonde se chega, mas como o processo mesmo de se construir esse caminho. Talvez se trate do desafio de buscar a "própria palavra”, mesmo sabendo que o 'próprio' carrega sempre o(s) outro(s), de se compreender, pois, que "sendo sujeito desejante, o sujeito-ensinante vive o eterno conflito de incompletude de significação acerca de suas ações de ensinância" (SANTOS, 2006, p. 29).

Talvez reformulações de caráter prático - exigir, por exemplo, que os diários sejam entregues ao longo do curso, 'forçando' uma interlocução - possam favorecer uma intervenção mais efetiva por parte do professor supervisor e, consequentemente, uma (re)escrita mais significativa por parte do professor em formação. Todavia, sabe-se que diálogo não é algo que se 'força', mas a expressão do desejo de dizer(-se) ao(s) outro(s) e ouvir suas palavras, de encontrar(-se) no(s) outro(s), enfim, de juntar fios na tentativa sempre ilusória - de findar a trama.

\section{Referências}

ALLWRIGHT, D.; BAILEY, K. M. Focus on the language classroom: an introduction to classroom research for language teachers. Cambridge: Cambridge University Press, 1991.

AUTHIER-REVUZ, J. Heterogeneidade mostrada e heterogeneidade constitutiva: elementos para uma abordagem do outro no discurso. In: AUTHIER-REVUZ, J. Entre a transparência e a opacidade: um estudo enunciativo do sentido. Porto Alegre: EDIPUCRS, 2004. p. 11-80.

BOHN, H. As exigências da pós-modernidade sobre a pesquisa em lingüística aplicada no Brasil. In: FREIRE, M.; ABRAHÃO, M. H. V.; BARCELOS, A. M. F. (Orgs.) Lingüistica Aplicada e contemporaneidade. Campinas: Pontes: ALAB, 2005. p. 11- 23. 
BRITO, C. C. P. Diários reflexivos de professores de língua inglesa em formação inicial: o outro que (me) confessa. In: SILVA, W. R. (Org.). Letramento do professor em formação inicial: interdisciplinaridade no estágio supervisionado da licenciatura. Campinas: Pontes, 2012. p. 139-163.

BROCK, M. N.; YU, B.; WONG, M. Journaling together; collaborative diarykeeping and teacher development. In: INTERNATIONAL CONFERENCE ON SECOND LANGUAGE TEACHER EDUCATION. Hong Kong, 1991. (Oral presentation).

CORACINI, M. J. R. F. A abordagem reflexiva na formação do professor de língua. In: CORACINI, M. J. R. F.; BERTOLDO, E. S. (Orgs.). O desejo da teoria e a contingência da prática: discursos sobre e na sala de aula: língua materna e língua estrangeira. Campinas: Mercado de Letras, 2003. p. 305-327.

FAIRCHILD, T. O professor no espelho: refletindo sobre a leitura de um relatório de estágio na graduação em Letras. Revista Brasileira de Linguística Aplicada, v. 10, p. 271-288, 2010.

FERREIRA, M. C. L. O quadro atual da análise de discurso no Brasil: um breve preâmbulo. In: INDURSKY, F; FERREIRA, M. C. L. (Orgs.). Michel Pêcheux e a análise do discurso: uma relação de nunca acabar. São Carlos: Claraluz, 2005. p. 13-22.

HILÁ, C. V. D. O gênero diário como instrumento catalisador na formação inicial. Travessias, v. 2, n. 1, 2008. Disponível em:

<http://e-revista.unioeste.br/index.php/travessias/article/view/2948>. Acesso em: 18 ago. 2012.

LIBERALI, F. C. O diário como ferramenta para a reflexão crítica. 1999. 166 p. Tese (Doutorado em Linguística Aplicada ao Ensino de Línguas) Pontifícia Universidade Católica de São Paulo, São Paulo.

MACHADO, A. R. O diário de leituras: introdução de um novo instrumento na escola. São Paulo: Martins Fontes, 1998.

MOITA LOPES, L. P. Lingüística Aplicada e vida contemporânea: problematização dos construtos que tem orientado a pesquisa. In: 
MOITA LOPES, L. P. (Org.). Por uma lingüistica aplicada INdisciplinar. São Paulo: Parábola, 2006. p. 85-107.

MOITA LOPES, L. P. Da aplicação de Linguística à Linguística Aplicada indisciplinar. In: PEREIRA, R. C.; ROCA, P. (Orgs.). Linguística Aplicada: um caminho com diferentes acessos. São Paulo: Contexto, 2009. p. 11-24.

NASCENTE, R. M. M. Formação reflexiva pré-serviço de professores de Língua Inglesa. Revista Intercâmbio, v. 18, p. 139-154, 2008.

PÊCHEUX, M. Semântica e discurso: uma crítica à afirmação do óbvio. 3. ed. Tradução Eni P. Orlandi et al. Campinas: Editora da UNICAMP, 1997 a.

PÊCHEUX, M. Análise automática do discurso. In: GADET, F.; HAK, T. (Orgs.). Por uma análise automática do discurso: uma introdução à obra de Michel Pêcheux. 3. ed. Tradução Bethania S. Mariani et al. Campinas: Editora da Unicamp, 1997b. p. 61-105.

PONZIO, A. Procurando uma palavra outra. São Carlos: Pedro \& João, 2010.

RAJAGOPALAN, K. Repensar o papel da lingüística aplicada. In: MOITA LOPES, L. P. (Org.). Por uma lingüistica aplicada INdisciplinar. São Paulo: Parábola, 2006. p. 149-168.

SANTOS, J. B. C. Discursividades e ensinância de línguas. In: BERTOLDO, E. S.; MUSSALIM, F. (Orgs.). Análise do Discurso: aspectos da discursividade no ensino. Goiânia: Trilhas Urbanas, 2006. p. 25-35.

SMITH, J. Teachers work and politics of reflection. American Educational Research Journal, v. 29, n. 2, p. 267-300, 1992. 